\title{
Involvement of Bone Marrow Megakaryocytes in the Formation of the Bone Marrow-Blood Barrier in Transgenic Mice
}

\author{
${ }^{1}$ Pawel Laskowski, ${ }^{1}$ Karol Ostrowski, ${ }^{1}$ Beata Klim, ${ }^{1}$ Katarzyna Kitlas, \\ ${ }^{1}$ Dorota Lemancewicz, ${ }^{2}$ Maria M. Winnicka and ${ }^{1}$ Janusz B. Dzieciol \\ ${ }^{1}$ Department of Human Anatomy, \\ ${ }^{2}$ Department of General and Experimental Pathology, \\ Medical University of Bialystok, 15-089 Bialystok, Poland
}

Received 2013-05-06, Revised 2013-06-24; Accepted 2013-09-19

\begin{abstract}
Mature cell release takes place through the hypothetical barrier- the bone marrow-blood barrier. It consists of blood vessels and cells that surround them. Such cells are, among others, megakaryocytes. They are involved in the release of platelets or other cellular components of blood. The amount and the development of megakaryocytes and thus the maturity of barrier depends on many factors. One of them is IL-6, which gene is located on the short arm of chromosome 7 (7p15-p21). The study was performed on wild-type mice (C57B4/6J) and on mice lacking the gene encoding IL-6 (IL-6 KO-C57B4/6J IL-6tm1 Kopf-/-). Bone marrow of all animals in both groups has been collected, fixed and stained. Megakaryocytes were identified in each microscopic specimen using immunohistochemical reaction with the CD61 antibody. Then all specimens were subjected to histomorphometric analysis. Statistically significant differences in the total number and size of magakariocytes was noted, which affects bone marrow-blood barrier functions. This could be used in the conventional treatment of cancer, respiratory diseases and coagulation disorders and in the treatment using nanoparticles.
\end{abstract}

Keywords: IL-6, Megakaryocytes, Transgenic Mice, Bone Marrow-Blood Barrier

\section{INTRODUCTION}

Bone marrow is the major haematopoietic organ. Between the bone trabeculae there is the haematopoietic tissue built up of progenitor cells, mature cells of the respective developmental pathways and the so called haematopoietic microenvironment with cells (macrophages, fibroblasts, endothelial cells), their receptors and the Extra Cellular Matrix (ECM) (Kidd et al., 2011; Charboard et al., 1996; Yamazaki and Allen, 1990). The ECM is a complex structure that constitutes the stroma of the cells present (Skora et al., 2006). It consists of three main components: proteoglycans, specialized cells (laminin, fibronectin, fibrillin) and structural proteins (collagen, elastin). It also contains such proteins as thrombospondin, hemonectin, cytokines and enzymes (e.g., Matrix Metallproteinases MMPs) (Visse and Nagase, 2003). The matrix is a "dynamic structure" which adapts to the changing cellular and extracellular relationships and promotes function of endothelial cells, including structural function (proliferation, cytoskeletal organization, cell shape) and regulation of transmitted signals (actions of cytokines and growth factors) (Jackson, 2002). Cell release from bone marrow to peripheral blood takes place through a hypothetical barrier separating these structures, the so called bone marrow-blood barrier (Tavassoli, 1979).

A well-developed system of blood vessels of varying calibre, including arterioles, central veins and venous sinuses, can be seen to surround the haematopoietic cells. Each sinus is composed of several layers: inner, outer and middle. The inner layer is formed by endothelial

Corresponding Author: Paweł Łaskowski, Department of Human Anatomy, Medical University of Białystok, Mickiewicz street 2A, 15-089 Białystok, Poland Tel: +48 857485662 
cells that closely adhere to each other. The outer layer consists of stromal cells of the bone marrow, macrophages and adipose cells which block the contact of progenitor cells with the sinusoidal lumen. The middle layer is made up of the incomplete basement membrane. Also megakaryocytes are frequently found in the perisinusoidal spaces (Italiano, 2013; Dzieciol, 1995).

Megakaryocytes are the largest $(12-150 \mu \mathrm{m})$ and least numerous $(0.04-0.08 \%)$ mononuclear cells of bone marrow (Dzieciol, 1995; Italiano, 2013; Machlus and Italiano, 2013; Arabanian et al., 2011; Deutsch and Tomer, 2006). In physiological conditions, in normal bone marrow, megakaryocytes are most common in close proximity to the vascular sinuses. They are derived from the Pluripotent Haematopoietic Stem Cell (PHSC) (Wu et al., 2005; Machlus and Italiano, 2013; Deutsch and Tomer, 2013; Arabanian et al., 2011; Kidd et al., 2011). The microscopic picture of bone marrow shows two types of megakaryocyte colonies: primitive, which form clusters, i.e., Burst Forming Unit-Megakaryocytes (BFU-MK) and more mature and smaller, Colony Forming UnitMegakaryocytes (CFU-MK) (Deutsch and Tomer, 2006). Maturation of megakaryocyte nucleus and cytoplasm may occur at different time points and thus the cells have different nuclear ploidi that may range from 2 to $64 \mathrm{~N}$ (most often $8 \mathrm{~N}$ or $16 \mathrm{~N}$ ) (Deutsch and Tomer, 2006; Machlus and Italiano, 2013).

The cytoplasm of a mature megakaryocyte is divided into three zones-perinuclear, intermediate and outer. The perinuclear zone contains the endoplasmic reticulum with numerous ribosomes, mitochondria, Golgi apparatus, microtubules and granules. The intermediate zone is a well-built Demarcation Membrane System (DMS) together with numerous organelles, later present in blood platelets (e.g., alpha granules). The outer zone contains mainly protein fibrils (Dzieciol, 1995; Italiano, 2013).

Perisinusoidal mature megakaryocytes generate two types of cytoplasmic processes: (1) small and short, arising from the peripheral part of the cytoplasm, devoid of cell organelles and (2) bigger and longer, derived from the intermediate layer, with numerous cytoplasmic structures. Short processes can adhere to endothelial cells and thus "hold" megakaryocytes close to the sinusoidal vessels and receive information necessary to regulate platelet release. On the other hand, long processes are capable of passing through micro-pores (up to $6 \mu \mathrm{m}$ in diameter) between endothelial cells to the lumen of the sinusoidal vessels (Mehdi and Makoto, 1981; Yeager et al., 1998; Italiano, 2013; Machlus and Italiano, 2013; Deutsch and Tomer, 2006; 2013; Deutsch et al., 2010). In this way, blood platelets are released via intravascular fragmentation. According to another theory, megakaryocytes take part in the release of other morphotic components to the peripheral blood. This phenomenon called emperipolesis involves internalization of one cell by another and next its migration directly to the peripheral blood. The process, which has not been fully elucidated, is similar to phagocytosis, although in emperipolesis, the absorbed cell is neither destroyed nor combines with the cytoplasmic structures of the megakaryocyte (Cashell and Buss, 1992; Dzieciol et al., 2001; Sable et al., 2009).

The number of megakaryocytes in the perisinusoidal spaces and thus the count of platelets released to the circulation vary and depend on many factors, including platelet demand, haematological disorders and the activity of stimulators and inhibitors of megakaryocytopoiesis. Williams et al. $(1981$; 1982) have proposed two-stage regulation of megakaryocyte development. The first is the Megakaryocyte-Colony Stimulating Factor (Meg-CSF) that was isolated from the urine of patients with aplastic anaemia. Meg-CSF stimulates the proliferation of young precursor cells towards megakaryocytes. The other is a heterogeneous group of substances that condition the growth and maturation of megakaryocytes. They directly affect precursor cells, exert an indirect effect through other substances, or acting synergistically stimulate megakaryocyte maturation. The stimulators include e.g., Thrombopoietin (TPO), Interleukin-3 (IL-3), Interleukin-6 (IL-6), Interleukin-11 (IL-11), c-Kit Ligand (KL), chemokines (SDF-1, FGF-4) and Erythropoietin (EPO) (Pawlak et al., 2008; Kidd et al., 2011; Deutsch et al., 2010; Donghua et al., 2011; Deutsch and Tomer, 2006). Burstein et al. (1992) found a significant in vivo acceleration of the thrombocytopoietic system in dogs exposed to low-dose radiation after administration of IL6 as compared to the animals that did not receive the supplementation.

The gene encoding IL-6, composed of 5 encoding segments located on the short arm of chromosome 7 (7p15-p21), is a pleiotropic cytokine of $21-28 \mathrm{kDa}$, varied biological activity and built up of 184 amino acids (Banas et al., 2006; Gadient and Patterson, 1999; Donghua et al., 2011). IL-6 acts through the stimulation of the tyrosine kinase receptor complex, IL-6R. The complex is built up of a subunit $\alpha$ (Il-6R $\alpha / g p 80)$ that recognizes and binds the ligand and a subunit $\beta$ (Il-6R/gp130), signal transducer, which affects transcription activity and gene expression. The combination of the ligand with the receptor subunit $\alpha$ results in conformation changes in the subunit $\beta$, leading to intracellular activation of the Signal Transducer and Activator of Transcription (STAT) proteins with the involvement of Jak kinases (Ara et al., 2009; Giuliani et al., 2004; Murray, 2007; Skiniotis et al., 
2005; Donghua et al., 2011). Interleukin-6 plays a key role in the immune response, inflammatory reaction, haematopoiesis and is the major factor involved in the induction of acute phase proteins (Hsu et al., 2002; Lukaszewicz et al., 2007; Scheller et al., 2006; Pini et al., 2011). It also regulates proliferation and differentiation of several haematopoietic cell lines, at various stages of their maturation (Kishimoto, 1989). In cooperation with IL-3, interlekin-6 stimulates the proliferation of granulocytes, macrophages, megakaryocytes and progenitor cells of the erythrocytic system (Ikebuchi et al., 1987; Ishibashi et al., 1989; Okada et al., 1992; Patchen et al., 1991).

IL-6 is produced by a number of cell types of e.g., the immune system ( $\mathrm{T}$ cells, B cells, monocytes, dendritic cells), fibroblasts, keratinocytes, vascular endothelial cells, bone marrow stroma, cells involved in connective tissue rebuilding (chondrocytes, osteoblasts), cardiomyocytes, renal mesangial cells, adipocytes and some cancer cells (Gwechenberger et al., 1999; Takabe et al., 2004; Visseren et al., 1999; Volk et al., 2000). IL-6 is also a myokine, i.e., the cytokine secreted by skeletal muscle. InductionofIL-6gene expressionin the muscle is mediated by numerousagents, including the levels of glycogen, calcium ions and reactive oxygen species that originate on exertion. It is the only one to appear already during physical exercise and its level may increase even 120 times.

The study objective was to assess the system of bone marrow megakaryocytes in IL-6 knock-out mice as compared to the mice with the gene encoding IL-6. The involvement of megakaryocytes in the formation of the bone marrow-blood barrier and histomorphometric parameters were assessed in the two groups.

\section{MATERIALS AND METHODS}

\subsection{Animals}

The study was conducted on two groups of male mice. The first group consisted of 5 wild strain mice (C57B4/6J), aged 18 months. The other group included 5 genetically modified animals, without the gene encoding IL-6 (IL-6 KO) (C57B4/6J IL-6 ${ }^{\text {tm1 }}$ Kopf-/ $\left.^{-}\right)$, aged 17 months. Till the day of the experiment, the mice were bred in the Centre for Experimental Medicine, Medical University of Bialystok and had free access to food and water. The experiment was performed in accordance with the guidelines of the local Bioethical Committee.

Genomic DNA was isolated from murine tails using Genomic mini kit (A and A Biotechnology, Gdańsk, Poland. Standard primers were used in PCR: F 5'AAGTGCATCATCGTTGTTCATAC-3'; R 5'CCATCCAGTTGCCTTCTTG-3' and commercially available DNA polymerase Taq "Marathon" (A and A Biotechnology, Gdańsk, Poland). Next, DNA was isolated by electrophoresis on $1 \%$ agarose gel with addition of ethidium bromide. The material obtained from the wild strain mouse involved DNA fragments of approximately $900 \mathrm{bp}$ in size, whereas from IL-6 KO mice-DNA fragments of about $1400 \mathrm{bp}$ (with additional neomycin fragments). In this way, the presence of the gene encoding IL-6 (wild strain mice) or its absence (transgenic mice) was confirmed.

Prior to the experiment, the animals were acclimated to laboratory conditions for 7 days. They were kept in the environment at a temperature of $22 \pm 1^{\circ} \mathrm{C}$ at $12 \mathrm{~h}$ light (07.00-19.00)/12h dark period (19.00-07.00).

The mice were killed by cervical dislocation and then, immediately, both femoral bones and sternum were collected from each of them.

\subsection{Morphological Analysis of Bone Marrow}

The tissue material was fixed in $10 \%$ buffered formalin and then decalcified using a dehydrating and decalcifying buffer composed of: a fixative solution-zinc chloride, $37-38 \%$ formaldehyde, ice acetate acid, distilled water; and decalcifying solution $-10 \%$ formic acid, 5\% formaldehyde. After a $24 \mathrm{~h}$ fixation, the material was embedded in paraffin blocks and then cut on a microtome into $6 \mu \mathrm{m}$ paraffin sections. The sections were then stained with haematoxylin and eosin and subjected to histopathological and histomorphometric analysis using a morphometric kit Olympus, consisting of an optical microscope Olympus BX41 with the Camedia 3030 digital photography system and $\mathrm{Cell}^{\mathrm{D}}$ Imaging Software for Life Science Microscopy.

Megakaryocytes were identified in each microscopic specimen routinely stained with haematoxylin and eosin. Their presence was confirmed by immunohistochemistry using CD61 antibody, Clone Y2/51 from DAKO (catalogue no. M 0753). DAKO EnVision ${ }^{\mathrm{TM}}+$ System, catalogue no. M 0753, diluted at 1:100, was used as a detection kit. Next, the assessment involved megakaryocyte count in the field of vision, per $1 \mathrm{~mm}^{2}$ of specimen area and in the vicinity of the sinusoidal vessels, the number of clusters and the number of clusters close to the vessels. The minimum of 3 megakaryocytes were referred to as a cluster. Other calculations included megakaryocyte circumference, surface area and Circular Deviation (CD), defined as $\mathrm{CD}=4 \pi \mathrm{A} / \mathrm{C} 2$ (C-circumference, A-surface area), giving the value of 1.0 for the ideal circular shape. Reduced CD indicates enhanced circumferential irregularities of the morphometrically assessed structure (Thiele et al., 1992). The results were then analysed and elaborated using a computer programme Statistica 10PL. Statistical analysis was performed with t-test (significance) and U Mann-Whitney test. Statistical significance was accepted for $\mathrm{p}<0.05$. 


\section{RESULTS}

The analysis of the involvement of bone marrow megakaryocytes in the formation of the bone marrowblood barrier concerned the evaluation of the total megakaryocyte count, their distribution in relation to the sinusoidal vessels and the number and location of clusters. A statistically significant difference was noted in the total megakaryocyte count between the two groups (mean 114.0 in wild strain mice vs 71.67 in transgenic mice, $p<0.05$ ). The comparison of the megakaryocyte count per $1 \mathrm{~mm}^{2}$ of specimen area and near the vessels, the number of clusters and clusters in the vicinity of the sinusoidal vessels showed no statistically significant differences. The mean surface area of megakaryocytes in bone marrow specimens of wild strain mice was $364.76 \mu \mathrm{m}^{2}$, whereas in transgenic mice-299.27 $\mu^{2}$ (statistically significant difference, $\mathrm{p}<0.05$ ). The circumference was $79.28 \mu \mathrm{m}$ and 71.09 $\mu \mathrm{m}$, respectively, the difference being statistically significant $\quad(\mathrm{p}<0.05)$. No statistically significant difference was found in the $\mathrm{CD}$, which was 0.71 in wild strain mice and 0.73 in transgenic mice $(p>0.05)$.

The results indicate a statistically significant difference in the total number and size of megakaryocytes in the groups studied. The differences in the topography and clustering tendency were observed but they were not statistically significant.

The findings are presented in Table 1.

Table 1. Numerical values used to assess the participation of megakaryocytes in formation of the bone marrow-blood barrier

\begin{tabular}{|c|c|c|c|c|}
\hline & & Wild strain mice & Transgenic mice & $\begin{array}{l}\text { Statistical } \\
\text { significance ( } \mathrm{p} \text { value) }\end{array}$ \\
\hline \multirow[t]{5}{*}{ MKC count } & Total & 228,00 & 215,00 & \multirow[t]{5}{*}{$\mathrm{p}<0,05$} \\
\hline & Mean & 114,00 & 71,67 & \\
\hline & Minimum & 87,00 & 65,00 & \\
\hline & Maximum & 141,00 & 82,00 & \\
\hline & SD & 38,18 & 9,07 & \\
\hline MKC count per & Total & 188,89 & 271,50 & \multirow[t]{5}{*}{$\mathrm{p}>0,05$} \\
\hline & Mean & 94,45 & 90,50 & \\
\hline \multirow{3}{*}{ specimen area } & Minimum & 93,55 & 69,89 & \\
\hline & Maximum & 95,34 & 110,21 & \\
\hline & SD & 1,27 & 20,18 & \\
\hline \multirow{5}{*}{$\begin{array}{l}\text { MKC count near } \\
\text { the vessels }\end{array}$} & Total & 82,00 & 105,00 & \multirow[t]{5}{*}{$\mathrm{p}>0,05$} \\
\hline & Mean & 41,00 & 35,00 & \\
\hline & Minimum & 27,00 & 26,00 & \\
\hline & Maximum & 55,00 & 40,00 & \\
\hline & SD & 19,80 & 7,81 & \\
\hline \multirow{5}{*}{ Number of clusters } & Total & 8,00 & 8,00 & \multirow{5}{*}{$\mathrm{p}>0,05$} \\
\hline & Mean & 2,66 & 2,66 & \\
\hline & Minimum & 0,00 & 0,00 & \\
\hline & Maximum & 7,00 & 6,00 & \\
\hline & SD & 3,78 & 3,06 & \\
\hline \multirow{5}{*}{$\begin{array}{l}\text { Number of clusters in } \\
\text { the vicinity of the } \\
\text { sinusoidal vessels }\end{array}$} & Total & 7,00 & 5,00 & \multirow[t]{5}{*}{$\mathrm{p}>0,05$} \\
\hline & Mean & 2,33 & 1,66 & \\
\hline & Minimum & 0,00 & 0,00 & \\
\hline & Maximum & 6,00 & 3,00 & \\
\hline & SD & 3,21 & 1,53 & \\
\hline \multirow{5}{*}{ Surface area } & Total & 53 & 91 & \multirow[t]{5}{*}{$\mathrm{p}<0,05$} \\
\hline & Mean & 364,76 & 299,27 & \\
\hline & Minimum & 169,25 & 129,13 & \\
\hline & Maximum & 697,83 & 610,37 & \\
\hline & SD & 132,65 & 103,79 & \\
\hline \multirow[t]{5}{*}{ Circumference } & Total & 53 & 91 & \multirow[t]{5}{*}{$\mathrm{p}<0,05$} \\
\hline & Mean & 79,28 & 71,09 & \\
\hline & Minimum & 51,61 & 45,74 & \\
\hline & Maximum & 112,17 & 107,67 & \\
\hline & SD & 14,95 & 13,20 & \\
\hline \multirow[t]{5}{*}{$\mathrm{CD}$} & Total & 53 & 91 & \multirow[t]{5}{*}{$\mathrm{p}>0,05$} \\
\hline & Mean & 0,71 & 0,73 & \\
\hline & Minimum & 0,48 & 0,55 & \\
\hline & Maximum & 0,84 & 0,86 & \\
\hline & SD & 0,09 & 0,06 & \\
\hline
\end{tabular}




\section{DISCUSSION}

Megakaryocytopoiesis is the process of megakaryocyte generation and maturation under the influence of the respective regulatory agents, including interleukin-6. IL-6 is a cytokine which by affecting murine bone marrow accelerates maturation of megakaryocytes. This is manifested by their enlargement and enhanced involvement in the formation of bone marrow-blood barrier and as proved by Kishimoto (1989), by an increase in their proliferative activity. In consequence, the effect leads to a rise in the total megakaryocyte count, to the production of the so called "immature" blood platelets and to increased accumulation of megakaryocytes in the vicinity of the sinusoidal vessels.

As revealed by the results obtained for the normal bone marrow of wild strain mice possessing the gene encoding IL-6 as compared to the IL-6 knock-out mice, megakaryocytes constitute a population of cells with substantially larger surface and circumference. This is particularly important for megakaryocyte involvement in the formation of bone marrow-blood barrier or production of platelets. The statistically significant differences in megakaryocyte circumference and surface area seem to suggest that when all the factors regulating proliferation and maturation are present, functionally mature cells are produced. However, according to the two-stage megakaryocytopoiesis regulation model and the current study findings, removal of even one component results in factor imbalance, causing disorders in the differentiation and maturation of thrombocytopoietic cells. Moreover, as shown by our research, lack of IL-6 leads to structural alterations in the bone marrow-blood barrier due to changes in megakaryocyte count and topography. Statistically significant differences are noticeable in the total megakaryocyte count.

Advances in medicine and in the related sciences frequently involve nanotechnology which uses molecules smaller than $10^{-9} \mathrm{~m}$ for clinical purposes. Numerous studies are being currently conducted on the use of drug molecules of that tiny size to act precisely in the disease focus, with no all-systemic effect. As reported by Suri et al. (2007) in order to achieve a desired therapeutic effect, scientists should have a profound knowledge, first of all of the molecular mechanisms underlying transmission of cell signals. Properly prepared nanomolecules can be employed not only in the treatment of cancers or respiratory diseases (Peppas and Blanchette, 2004; Pison et al., 2006; Schatzlein, 2006; Stylios et al., 2005; Suri et al.,
2007; Yokoyama, 2005). Due to the effect they exert on the bone marrow system, nanomolecules can also contribute to the treatment of e.g., thrombocytopenia-related disorders.

\section{CONCLUSION}

The current findings indicate that transgenic mice can be used in experimental studies whose results can be utilized in nanotechnology. They also show that the pleiotropic interleukin- 6 can be applied in the analysis of pharmaceutical drugs administered to treat coagulation disorders. Additionally, current researchsuggeststhe possibility of usingIL-6 in the treatment of orthotopic renal cell cancer with a high therapeutic potential (Wysocki et al., 2010).

\section{ACKNOWLEDGMENT}

Submitting to print a manuscript of this study, the authors do not report occurrence of any potential conflict of interests. All authors hereby declare that neither the submitted materials nor portions therefore have been published previously or are under consideration for publication elsewhere. All authors certify that all listed authors participated meaningfully and significantly in the study and that they have seen and approved the final manuscript. All authors are in agreement with the content of the manuscript. All authors agree to the conditions outlined in the copyright assignment form.

\section{REFERENCES}

Ara, T., L. Song, H. Shimada, N. Keshelava and H.V. Russell et al., 2009. Interleukin-6 in the bone marrow microenvironment promotes the growth and survival of neuroblastoma cells. Cancer Res., 69: 329-337. DOI: 10.1158/0008-5472.CAN-08-0613, PMID: 19118018

Arabanian, L., S. Kujawski, I. Habermann, G. Ehninger, A. Kiani, 2011. Regulation of fas/fas ligandmediated apoptosis by nuclear factor of activated $\mathrm{T}$ cells in megakaryocytes. Br. J. Haematol., 156: 523534. DOI: 10.1111/j.1365-2141.2011.08970.x, PMID: 22171718

Banas, M., M. Olszanecka-Glinianowicz and B. Zahorska-Markiewicz, 2006. Rola czynnika martwicy nowotworow i interleukiny-6 w zespole policystycznych jajnikow. Pol. Merk. Lek., 125: 489-491.

Burstein, S.A., T. Down, P. Friese, S. Lynam and S. Anderson et al., 1992. Thrombocytopoiesis in normal and sublethally irradiated dogs: Response to human interleukin-6. Blood, 80: 420-428. 
Cashell, A.W. and D.H. Buss, 1992. The frequency and significance of megakaryocytic emperipolesis in myeloproliferative and reactive states. Annals Hematol., 64: 273-276.

Charboard, P., M. Tavian, L. Humeau and B. Peault, 1996. Early ontogeny of the human marrow from long bones: an immunohistochemical study of hematopoiesis and its microenvironment. Blood, 87: 4109-4119.

Deutsch, V. and A. Tomer, 2013. Advances in megakaryocytopoiesis and thrombopoiesis: From bench to bedside. Br. J. Haematol., 161: 778-793. DOI: $10.1111 /$ bjh.12328

Deutsch, V., B.Z. Katz and A. Tomer, 2010. Megakaryocyte development and platelet production in normal and disease states. Harefuah, 149: 291297. PMID: 20929068

Deutsch, V.R. and A. Tomer, 2006. Megakaryocyte development and platelet production. Br. J. Haematol., 134: 453-466. DOI: 10.1111/j.13652141.2006.06215.x

Donghua, H., T. Chen, M. Yang, X. Zhu and C. Wang et al., 2011. Small Rab GTPase Rab7b promotes megakaryocytic differentiation by enhancing IL-6 production and STAT3-GATA-1 association. J. Mol. Med., 89: 137-150. Doi: 10.1007/s00109010-0689-z

Dzieciol, J., 1995. Megakariocyty szpiku jako elementy bariery szpik-krew. Polskie Archiwum Medycyny Wewnetrznej, 93: 433-438.

Dzieciol, J., D. Lemancewicz, J. Kloczko, W. Boguslowicz and A. Lebelt, 2001. Megakaryocytes emperipolesis in bone marrow of the patients with non-Hodgkin's lymphoma. Folia Histochem. Cytobiol., 39: 142-143. PMID: 11820577

Gadient, R. and P. Patterson, 1999. Leukemia inhibitory factor, interleukin-6 and other cytokines using the GP 130 transducing receptor: Roles in inflammation and injury. Stem Cells, 17: 127-137. DOI: $10.1002 /$ stem. $170127 /$ pdf

Giuliani, N., P. Lunghi, F. Morandi, S. Colla and S. Bonomini et al., 2004. Downmodulation of ERK protein kinase activity inhibits VEGF secretion by human myeloma cells and myeloma-induced angiogenesis. Leukemia, 18: 628-635. DOI: 10.1038/sj.leu.2403269

Gwechenberger, M., L.H. Mendoza and K.A. Youker, 1999. Cardiac myocytes produce interleukin-6 in culture and in viable border zone of reperfused infarctions. Circulation, 99: 546-551. DOI: 10.1161/01.CIR.99.4.546
Hsu, H.C., Y.M. Lee and W.H. Tsai, 2002. Circulating levels of thrombopoietic and inflammatory cytokines in patients with acute myeloblastic leukemia and myelodysplastic syndrome. Oncology, 63: 64-69. DOI: 10.1159/000065722

Ikebuchi, K., G.G. Wong, S.C. Clark, J.N. Ihle and Y. Hirai et al., 1987. Interleukin 6 enhancement of interleukin 3-dependent proliferation of multipotential hemopoietic progenitors. Proc. Nat. Acad. Sci. USA., 84: 9035-9039. PMID: 3501121

Ishibashi, T., H. Kimura and Y. Shikama, 1989. Human interleukin- 6 is a direct promoter of maturation of megakaryocytes in vitro. Proc. Nat. Acad. Sci. USA., 86: 5953-5957.

Italiano, J.E., 2013. Unraveling mechanisms that control platelet production. Semin. Thromb. Hemost., 39: 15-24. DOI: $10.1055 / \mathrm{s}-0032-1331157$

Jackson, C., 2002. Matrix metalloproteinases and angiogenesis. Curr. Opin. Nephrol. Hypertension, 11: 295-299.

Kidd, S., C. Bueso-Ramos, S. Jagan, L.A. Paganessi and L.N. Boggio et al., 2011. In vivo expansion of the megakaryocyte progenitor cell population in adult CD26-deficient mice. Exp. Hematol., 39: 580-590. DOI: 10.1016/j.exphem.2011.01.012

Kishimoto, T., 1989. The biology of interleukin-6. Blood, 74: 1-10.

Lukaszewicz, M., B. Mroczko and M. Szmitkowski, 2007. Znaczenie kliniczne interleukiny 6 (Il-6) jako czynnika rokowniczego w chorobie nowotworowej. Polskie Archiwum Medycyny Wewnetrznej, 117: 247-251.

Machlus, K.R. and J.E. Italiano, 2013. The incredible journey: From megakaryocyte development to platelet formation. J. Cell Biol., 201: 785-796. DOI: 10.1083/jcb.201304054

Mehdi, T. and A. Makoto, 1981. Migration of entire megakaryocytes through the marrow-blood barrier. Br. J. Heamatol., 48: 25-29. DOI: 10.1111/j.13652141.1981.00025.x

Murray, P.J., 2007. The JAK-STAT signaling pathway: Input and output integration. J. Immunol., 178: 2623-2629.

Okada, S., H. Nakauchi, K. Nagayoshi, M. Nakamura and Y. Miura et al., 1992. Synergistic effect of IL-3 and IL6 on highly enriched murine hemopoietic progenitors. Exp. Hematol., 20: 546-551. PMID: 1350248 
Patchen, M.L., T.J. MacVittie, J.L. Williams, G.N. Schwartz and L.M. Souza, 1991. Administration of interleukin-6 stimulates multilineage hematopoiesis and accelerates recovery from irradiation-induced hematopoietic depression. Blood, 77: 472-480.

Pawlak, J., J. Dzieciol, M. Mantur and D. Pawlak, 2008. Megakaryocytes and platelets in experimentally induced renovascular hypertension $(2 \mathrm{~K} 1 \mathrm{C})$ in rats. Postepy Higieny Medycyny Doswiadczalnej, 62: 241-248.

Peppas, L.B. and J.O. Blanchette, 2004. Nanoparticle and targeted systems for cancer therapy. Adv. Drug Delivery, 56: 1649-1659. DOI: 10.1016/j.addr.2004.02.014

Pini, M., D.H. Rhodes and G. Fantuzzi, 2011. Hematological and acute-phase responses to dietinduced obesity in IL-6 KO mice. Cytokine, 56: 708-716. DOI: 10.1016/j.cyto.2011.09.015

Pison, U., T. Welte, M. Giersig and D.A. Groneberg, 2006. Nanomedicine for respiratory diseases. Eur. J. Pharmacol., 533: 341-350. DOI: 10.1016/j.ejphar.2005.12.068

Sable, M.N., K. Sehgal, V.S. Gadage, P.G. Subramanian and S. Gujral, 2009. Megakaryocytic emperipolesis: A histological finding in myelodysplastic syndrome. Ind. J. Pathol. Microbiol., 52: 599-600. DOI: 10.4103/0377-4929.56153

Schatzlein, A.G., 2006. Delivering cancer stem cell therapies- A role for nanomedicines? Eur. J. Cancer, 42: 1309-1315. DOI: 10.1016/j.ejca.2006.01.044

Scheller, J., N. Ohnesorge and S. Rose-John, 2006. Interleukin-6 (IL-6) trans-signaling in chronic inflammation and cancer. Scandinavian J. Immunonol., 63: 321-329. DOI: 10.1111/j.13653083.2006.01750.x

Skiniotis, G., M.J. Boulanger, K.C. Garcia and T. Walz, 2005. Signaling conformations of the tall cytokine receptor gp130 when in complex with IL-6 and IL-6 receptor. Nature Struct. Mol. Biol., 12: $545-551$.

Skora, J., J. Biegus, A. Pupka, P. Barc and J. Sikora et al., 2006. Molecularbasics of angiogenesis. Postepy Higieny Medycyny Doswiadczalnej, 60: 410-415.

Stylios, G.K., P.V. Giannoudis and T. Wan, 2005. Applications of nanotechnologies in medical practice. Int. J. Care Injured, 36S: S6-S13. DOI: 10.1016/j.injury.2005.10.011
Suri, S.S., H. Fenniri and B. Singh, 2007. Nanotechnologybased drug delivery systems. J. Occupat. Med. Toxicol., 2: 16-21. DOI: 10.1186/1745-6673-2-16

Takabe, W., Y. Kanai and A. Chairoungdua, 2004. Lysophosphatidylcholine enhances cytokine production of endothelial cells via induction of Ltype amino acid transporter 1 and cel surface antygen 4F2. Arteriosclerosis. Thrombosis Vascular Biol., 24: 1640-1645. DOI: 10.1161/01.ATV.0000134377.17680.26

Tavassoli, M., 1979. The marrow blood barrier. Br. J. Haematol., 41: 297-302. DOI: 10.1111/j.13652141.1979.tb05862.x

Thiele, J., B.R. Titius, C. Kopsidis and R. Fischer, 1992. Atypical micromegakaryocytes, promegakaryoblasts and megakaryoblasts: A critical evaluation by immunohistochemistry, cytochemistry and morphometry of bone marrow trephines in chronic myeloid leukemia and myelodysplastic syndromes. Virchows Arch. B, 62: 275-282. DOI: 10.1007/BF02899693

Visse, R. and H. Nagase, 2003. Matrix metalloproteinases and tissue inhibitors of metalloprot.einases structure, function biochem. Circulat. Res., 92: 827-839. DOI: 10.1161/01.RES.0000070112.80711.3D

Visseren, S.L., M.S. Verkerk and K.P. Bouter, 1999. Interleukin- 6 production by endothelial cells after infection with influenza virus end cytomegalovirus. J. Laboratory Clin. Med., 134: 623-630. DOI: 10.1016/S0022-2143(99)90103-8

Volk, T., M. Hensel, H. Schuster and W.J. Kox, 2000. Secretion of MCP-1 and Il-6 by cytokine stimulated production of reactive oxygen species in endothelial cells. Mol. Cellular Biochem., 206: 105-112. DOI: 10.1023/A:1007059616914

Williams, N., H. Jackson, P. Ralph and I. Nakoinz, 1981. Cell interactions influencing murine marrow megakaryocytes: Nature of the potentiator cell in bone marrow. Blood, 57: 157-163.

Williams, N., R.R. Eger, H.M. Jackson and D.J. Nelson, 1982. Two-factor requirement for murine megakaryocyte colony formation. J. Cellular Physiol., 11: 101. DOI: 10.1002/jcp.1041100116

$\mathrm{Wu}$, S., A. Korte, C. Kebelmann-Betzing, R. Gessner and G. Henze et al., 2005. Interaction of bone marrow stromal cells with lymphoblasts and effects of prednisolone on cytokine expression. Leukemia Res., 29: 63-72. DOI: 10.1016/j.leukres.2004.04.018 
Wysocki, P.J., U. Kazimierczak, W. Suchorska, M. Kotlarski and J. Malicki et al., 2010. Gene-modified tumor vaccine secreting a designer cytokine HyperInterleukin-6 is an effective therapy in mice bearing orthotopic renal cell cancer. Cancer Gene Therapy, 17: 465-475. DOI: $10.1038 /$ cgt.2010.2

Yamazaki, K. and T.D. Allen, 1990. Ultrastructural morphometric study of efferent nerve terminals on murine bone marrow stromal cells and the recognition o a novel anatomical unit: The 'neuroreticular complex. Am. J. Anatomy, 187: 261-276. DOI: 10.1002/aja.1001870306
Yeager, M., V.M. Unger and M.M. Falk, 1998. Synthesis, assembly and structure of gap junction intercellular channels. Curr. Opinion Struct. Biol., 8: 517-524. DOI: 10.1016/S0959-440X (98)80131-0

Yokoyama, M., 2005. Drug targeting with nano-sized carrier systems. J. Artif. Organs, 8: 77-84. DOI: 10.1007/s10047-005-0285-0, PMID: 16094510 